\title{
Left Ventricular Assist Device as Destination Therapy: a State of the Science and Art of Long-Term Mechanical Circulatory Support
}

\author{
Thomas C. Hanff ${ }^{1} \cdot$ Edo Y. Birati ${ }^{1}$ \\ Published online: 21 October 2019 \\ (C) Springer Science+Business Media, LLC, part of Springer Nature 2019
}

\begin{abstract}
Purpose of Review The purpose of this review is to synthesize and summarize recent developments in the care of patients with end-stage heart failure being managed with a left ventricular assist device (LVAD) as destination therapy.

Recent Findings Although the survival of patients treated with LVAD continues to improve, the rates of LVAD-associated complication, such as right ventricular failure, bleeding complications, and major infection, remain high, and management of these patients remains challenging.

Summary The durability and hemocompatibility of LVAD support have greatly increased in recent years as a result of new technologies and novel management strategies. Challenges remain in the comprehensive care of patients with destination therapy LVADs, including management of comorbidities and optimizing patient function and quality of life.
\end{abstract}

Keywords LVAD $\cdot$ Destination therapy $\cdot$ Adverse events $\cdot$ Long-term $\cdot$ Management

\section{Introduction}

Heart failure is a global pandemic and one of the leading causes of morbidity and mortality, affecting 26 million people worldwide and 5.7 million people in the USA [1]. It is estimated that the $5 \%-10 \%$ of this patient population have severe heart failure symptoms despite optimal medical therapies and may benefit from advanced heart failure therapies. [2]

The REMATCH [3] trial (Randomized Evaluation of Mechanical Assistance for the Treatment of Congestive Heart Failure) validated long-term mechanical circulatory support with a left ventricular assist device (LVAD) as a novel strategy in the management of patients with advanced systolic heart failure ineligible for heart transplantation, a strategy termed Destination Therapy (DT). Up to this point,

This article is part of the Topical Collection on Updates in Advanced Heart Failure

Edo Y. Birati

edo.birati@pennmidicine.upenn.edu

1 Department of Medicine Cardiovascular Division, Perelman School of Medicine, University of Pennsylvania, Philadelphia, PA, USA mechanical support platforms had been employed only as a temporizing measure until time of cardiac transplant. The results in REMATCH were dramatic: with implantation of a first-generation pulsatile-flow LVAD (the HeartMate XVE), patients experienced a $48 \%$ reduction in mortality and improved quality of life compared to optimal medical therapy-the largest relative survival benefit of any heart failure trial to date [4]. Still, 1 - and 2-year survival remained poor at $52.1 \%$ and $24.7 \%$ - far inferior to heart transplantation, partially due to mechanical breakdown of the pulsatile technology.

In an effort to improve the durability of the devices, continuous-flow LVAD (cf-LVAD) technology was developed within a decade. Continuous-flow platforms challenged fundamental concepts about the physiologic role of pulsatility in end-organ perfusion, but early success in the HeartMate II (HM2) trial [5] in 2009 led to universal adoption of the cfLVAD and precipitous growth of the DT strategy over the course of the decade. In 2010, only $35 \%$ of patients were implanted as DT compared to $65 \%$ implanted as a bridge to transplant (BTT) or bridge to transplant candidacy (BTC). By 2017, 49\% of cf-LVADs were implanted as DT. With the new transplant allocation system established in October 2018, the percentage of patients treated with LVAD as BTT has declined 
significantly, and it is estimated that $80-90 \%$ of the implants in the USA will be BTC or DT.

Since 2006, almost 20,000 patients in the USA have been implanted with a cf-LVAD, including over 2500 implantations in each recent year [6]. Survival of patients with the cf-LVAD has greatly increased and continues to improve. In the most recent INTERMACS report, including data up to 2016 from BTT, DT, and BTC patients, 1- and 5-year survival with cfLVADs was $83 \%$ and $46 \%$, respectively [6]. Yet, the use of cfLVADs has been plagued by a high rate of adverse events, including stroke, device thrombosis, right heart failure, infection, and bleeding. In addition, DT patients continue to face numerous functional limitations and quality of life stressors that are not addressed by — or even made worse by — LVAD implantation [7, 8]. However, a paradigm shift is underway in the care of DT LVAD patients, and a number of technological breakthroughs and critical clinical insights in recent years have helped mitigate many of these challenges.

This review will focus on strategies for the long-term management of DT patients after the implantation of an LVAD. It must be noted, however, that the first step towards long-term patient optimization after LVAD is appropriate patient selection and LVAD timing, complex topics outside the scope of this review. Fundamentally, however, the risk of mortality and morbidity from medically managed heart failure must be weighed against the risk of mortality and morbidity after LVAD [9] and these discussions must occur in conjunction with patients and their families with early involvement of palliative care specialists. Risk scores including the Seattle Heart Failure Model [10] and objective functional testing via the 6-min walk and peak oxygen consumption can help stratify the risk of heart failure mortality. This can be compared to predicted survival after LVAD, using tools such as the PennColumbia risk score that recently modeled post-LVAD survival up to 1 year [11]. Nevertheless, individualized decisionmaking is key, and the rapid technological progress occurring every year requires continued reassessment of LVAD timing and selection criteria in order to optimize patient outcomes.

\section{Destination Therapy Platforms in the Modern Era}

Today, three commonly used durable devices have FDA approval in the USA for DT implantation: the HM2 (Abbott Inc., Lake Bluff, IL), the HVAD (Medtronic Ltd., Fridley, MN), and the HeartMate III (HM3) (Abbott Inc., Lake Bluff, IL). The hemodynamic performance of each cf-LVAD device can be compared via an "HQ curve," which details the relationship between pump flow at a given speed as a function of the pressure difference across the pump $\left(\Delta P=P_{\text {out }}-P_{\text {in }}\right)[12]$. Recent observational and trial data have demonstrated differences in clinical outcomes between devices, detailed below, that are related to their underlying biomechanical operating characteristics. Optimal patient selection for LVAD therapy and long-term DT management requires an understanding of these developments.

\section{HeartMate 2}

The first FDA-approved device for DT was the HM2 in January 2010 after survival and device durability was shown to be superior to pulsatile LVAD technology [5] and it remained the only device with DT approval for 7 years. The HM2 is unique among DT-approved platforms in its axialflow design, hydrodynamic profile, required thoracoabdominal placement, and mechanical bearingsupported rotor [5]. The axial-flow impeller, which functions hydrodynamically as an Archimedes screw pushing blood from the inlet to the outlet, exhibits a linear decline in flow as $\Delta P$ increases [13]. Two clinical properties emerge from this: first, axial-flow devices continue to pull volume even when left ventricular (LV) filling pressure is reduced, such as in hypovolemia or right ventricular (RV) dysfunction. Under these conditions, HM2 patients are prone to suction events, accelerated hemolysis, further impaired RV performance, or worsened tricuspid regurgitation, though the device attempts to overcome this by dropping the pump speed temporarily when a low pulsatility index is detected. Conversely, in high afterload states, the axial-flow pump has a favorable response with a greater ability to maintain output—albeit less so than the native LV [14].

In 2011 and 2012, INTERMACS surveillance detected a 6fold increase in the rate of pump thrombosis in HM2 recipients $[15,16]$, accompanied by a $7 \%$ absolute decrease in freedom from device exchange or death at 6 months. The exact cause for the increase in the rate of thrombosis remains unclear. A root cause analysis uncovered several contributing etiologies, including mechanical bearings that make direct contact with the housing chamber, inadequate anticoagulation or antiplatelet therapy, partial obstruction of the inflow cannula when angled towards the free wall, and contribution from a revised bend-relief component that was capable of generating turbulence if fully or partially dislodged $[15,17]$. The PREVENT trial [18] later studied a multifactorial approach to mitigate pump thrombosis in HM2 recipients that addressed several of these underlying issues. Centers were instructed to implant the inflow cannula parallel to the septum to minimize obstruction, to keep pump speed above 9000 RPM, to keep mean arterial blood pressure $<90 \mathrm{mmHg}$, and to start a heparin bridge within $48 \mathrm{~h}$ of implantation. If no significant bleeding occurred, centers were to start aspirin within 2-5 days and to reach an INR goal of 2.0-2.5 with Coumadin within 57 days after implantation. Although the study had significant methodologic limitations - there was no control arm and follow-up was only 6 months-only $2.9 \%$ of patients 
experienced pump thrombosis at 3 months and $4.8 \%$ at 6 months. These rates were lower than any historical controls at the time, and most centers adopted comparable regimens as a result. However, in the Momentum trial, which included a control group of patients treated with HM2, the rate of pump thrombosis among patients on HM2 support remained high at rates of $13.9 \%$ [19].

\section{HVAD}

The HeartWare HVAD represented the first 3rd generation cfLVAD [20]. It operates via a centrifugal-flow platform, allowing for a considerably smaller-sized pump that could be implanted entirely within the intrapericardial space. Centrifugal flow devices, which generate flow by "throwing" blood tangential to their blades, modify the HQ relationship; more significant changes in flow result from relatively small changes in $\Delta P$ across the pump. While this renders the pump flow more susceptible to changes in afterload, it is also less susceptible to suction events from LV underfilling and offers more intrinsic pulsatility in coupling with the native cardiac cycle $[14,21,22]$. The HVAD introduced a novel bearing design that uses combined hydrodynamic and magnetic forces to completely suspend the impeller when spinning, generating a wider central blood channel with lower theoretical propensity towards thrombus deposition. However, significant blood trauma may still occur in the thin film of blood separating the rotating and stationary surface [23], and von Willebrand multimer profiles appear similar between the HVAD and the HM2 [24]. Lastly, the HVAD was updated more recently to include an optional periodic speed modulation feature (the "Lavare cycle") that allows alterations of flow within the LV, potentially mitigating blood stasis through improved ventricular washout $[25,26]$. When turned on, the Lavare cycle drops the set speed by $200 \mathrm{rpm}$ for $2 \mathrm{~s}$ then increases the pump speed by $400 \mathrm{rpm}$ (i.e., $200 \mathrm{rpm}$ above the starting point) for $1 \mathrm{~s} \mathrm{[27],}$ repeating this cycle once per minute. It is thus designed for improved LV washout rather than pulsatility, and in vitro mock loop studies have suggested a decreased incidence of thrombus formation in the LV or ingested by the pump [25]. These findings have not been evaluated clinically in a randomized trial. Lavare was approved for commercial use in the USA in 2018, and the worldwide utilization rate was $87 \%$ in a study from the post-approval Registry to EValuate the HeartWare Left Ventricular Assist System (ReVOLVE). [25]

The HVAD had been in use during the early part of the 2010 s as a BTT platform following results of the ADVANCE trial, though questions remained regarding the risk of stroke associated with the device. In 2017, results from the ENDURANCE trial were published comparing the HVAD to the HM2 in DT patients [28]. The primary noninferiority endpoint of the study was a composite of survival free from disabling stroke or device replacement at 2 years. In the intention to treat analysis, the primary endpoint was achieved in $55.4 \%$ of HVAD recipients and $59.1 \%$ of the HM2 recipients, a difference of $3.7 \%$ with an upper $95 \%$ confidence bound of $12.56 \%$ that met the noninferiority threshold of $15 \%$. Post hoc analysis in the per-protocol arms also showed fewer HVADs with device malfunction or failure $(8.8 \%$ vs $16.2 \%, p=0.03$ ), primarily from a lower incidence of pump thrombosis. However, HVAD recipients were found to have a higher rate of stroke (ischemic or hemorrhagic), right heart failure, and sepsis compared to the HM2 arm [28].

In retrospective analyses of the ENDURANCE and ADVANCE trials, it appeared that the increase in stroke was seen primarily when mean arterial pressure (MAP) rose above $90 \mathrm{mmHg}$ and most events occurred in the first 6 months after implantation $[29,30]$. This motivated the ENDURANCE Supplemental Trial [30] in which subjects were randomly allocated to either the HVAD plus a strict blood pressure protocol ( $\leq 85 \mathrm{mmHg}$ by automated cuff or $\leq 90$ by Doppler cuff) or the HM2 with standard-of-care blood pressure management. The primary outcome was the rate of neurologic injury at 12 months, including stroke, transient ischemic attack, or spinal cord injury. The trial failed to meet a prespecified noninferiority margin of $6 \%$ for the upper confidence limit: HVAD recipients had a $14.7 \%$ incidence of neurologic injury compared to $12.1 \%$ in the HM2 arm, with a $95 \%$ upper confidence bound of $10.7 \%$. Nevertheless, the rate of ischemic stroke was reduced by $24 \%$ and rate of hemorrhagic stroke was reduced by $50 \%$ in the strict blood pressure group. Moreover, the device demonstrated superiority in a secondary endpoint of 12-month freedom from death, disabling stroke, device failure requiring exchange, explantation, or urgent transplantation $(76.1 \%$ vs $66.9 \%, p=0.04)$, and the rate of right heart failure in this subsequent trial was no different between the two arms [30].

A thoracotomy approach for HVAD implantation was recently studied in the LATERAL trial [31] with the expectation that this could reduce surgical morbidity and mortality among select patients. High survival rates were observed at 1 and 2 years ( $89 \%$ and $87 \%$, respectively), noting that this study only included patients who were BTT (74\%) and BTC (26\%), limiting comparison to results from DT studies. Nevertheless, the high survival rates in LATERAL have stimulated the possibility that this strategy could be studied in select DT patients who do not require sternotomy for concomitant procedures (e.g., valve surgery and moderate likelihood of RVAD) and who have no evidence of LV thrombus.

\section{HeartMate III}

Continued efforts to improve cf-LVAD hemocompatibility led to the development of the HM3. Like the HVAD, the HM3 was built around a centrifugal-flow, intrapericardial design. The HM3, however, utilizes a novel bearing design that is 
fully magnetically levitated (i.e., MagLev technology), resulting in even wider blood flow pathways and significantly reduced shear stress [32] without the need for hydrodynamic thrust. In addition, the HM3 implemented an artificial pulsatility algorithm: every $2 \mathrm{~s}$, the pump drops its speed by $2000 \mathrm{rpm}$ for $0.15 \mathrm{~s}$ then increases the speed by $4000 \mathrm{rpm}$ for $0.2 \mathrm{~s}$ before returning to the set speed. Such augmented pulsatility offers several hypothetical benefits that are of interest in future analyses, including increased LV washout, delayed onset of aortic insufficiency [33], and reduced incidence of arteriovenous malformations (AVMs) [34]. However, the fixed time interval of speed fluctuations is not coupled to the native cardiac cycle [35] so the actual degree of added pulsatility depends on both the magnitude of underlying contractility and the length of the cardiac cycle.

The MOMENTUM study evaluated 2-year outcomes of patients who were randomly allocated to either HM3 or HM2 devices [19]. Study investigators included patients irrespective of clinical intent for the LVAD, arguing that the practical and physiologic distinctions between DT, BTT, BTC, and bridge to recovery groups have become increasingly arbitrary [36]. The primary outcome-2-year survival free of disabling stroke or reoperation to replace or remove a malfunctioning device - was met in $76.9 \%$ of HM3 patients vs $64.8 \%$ of HM2 patients $(p<0.001)$, and no interaction was seen between the primary endpoint and the therapeutic intent of the device [37]. The largest driver of the primary outcome was a $14.6 \%$ absolute reduction in pump thrombosis rates with the HM3. Secondary endpoints also revealed a $9.1 \%$ absolute reduction in the overall rate of stroke driven primarily by a reduction in minor strokes, though rates of disabling stroke were comparable in both study arms. Significantly fewer bleeding events were also seen in the HM3 arm $(43.7 \%$ vs $55 \%, p<0.001)$ of MOMENTUM, underscoring the developing concept of hemocompatibility-related adverse events (HRAEs) that share overlapping pathophysiology rather than representing opposite ends of a bleeding/clotting spectrum [38, 39]. However, while intra-pump thrombosis showed a dramatic decrease in MOMENTUM, a later problem with outflow graft obstruction was detected in registry surveillance at a $0.72 \%$ incidence. This phenomenon was attributed to accumulated rotational stress at the bend relief culminating in twisting of the outflow graft and thrombus formation [40, 41]. In cases of low flows occurring in $\mathrm{HM} 3$ patients, it is recommended to conduct a $\mathrm{CT}$ angiography of the chest to rule out outflow graft twisting.

The sizable reduction in pump thrombosis events with the HM3 has generated great interest in utilizing a reduced anticoagulation regimen as a new strategy in HM3 recipients. The preliminary safety and feasibility of this strategy were evaluated in the MAGENTUM 1 study. Though non-randomized, among $15 \mathrm{HM} 3$ patients transitioned to a low INR strategy (1.5 to 1.9) 6 weeks post-implantation, no patients developed thrombotic events by 6 months. This is consistent with a similar post hoc analysis in MOMENTUM that showed no impact of antithrombotic regimen on stroke rates after device implantation [42]. Among HM3 patients with an increased bleeding risk, these data support consideration of a reduced anticoagulation regimen. However, further randomized evaluation of these concepts is necessary prior to more generalized adoption of this strategy, and the current recommendation remains to continue current anticoagulation regimen with INR goal of 2.0-3.0 and antiplatelet regimen with aspirin.

\section{Adverse Events in cf-LVAD Recipients}

Use of the cf-LVAD in DT populations has greatly improved survival. However, numerous adverse events continue to afflict LVAD recipients in spite of recent technological improvements [43]. Given the scarcity of donor hearts, there is a continued hope that LVADs will ultimately supplant cardiac transplantation as the gold standard therapy for end-stage heart failure [44]. That shift can take place only when medical and technological advances further mitigate adverse LVAD events and quality of life issues in the short and long term. Table 1 provides a summary of these adverse events, preliminary diagnostic steps, and management considerations.

\section{Pump Thrombosis}

Though device hemocompatibility is improving, pump thrombosis remains a significant adverse outcome in cf-LVAD recipients. High awareness is essential for early diagnosis of this severe complication. Nevertheless, early medical intervention for moderately elevated LDH levels (2.5 to 3.2 times the upper limit of normal) may increase the likelihood of successful resolution of hemolysis without the need for surgical intervention $[45,46]$. Thus, early thrombosis detection is critically important in all LVAD platforms, yet accurate and timely diagnosis can be challenging. Clinical manifestations vary widely. Patients will classically manifest with worsening heart failure, a new thromboembolic event, or typical changes in pump parameters, but they may also present asymptomatically [47]. In general, biomarkers of hemolysis (LDH, plasma free hemoglobin) and device interrogation (flows, power and pulsatility index for HM2 or HM3, and power by log file analysis for HVAD) should be combined with clinical symptoms to improve diagnostic sensitivity and specificity [48-50].

Treatment of pump thrombosis varies according to the pump. Although few patients may improve with unfractionated heparin alone, the improvement is usually temporary and associated with high recurrence rate and increased risk of stroke. HVAD patients with typical log files may benefit from treatment with thrombolytic therapy. In all HM2 patients and in HVAD patients not responding to thrombolysis, pump exchange is the treatment of choice [51, 52]. In all 
Table 1 Considerations for prevention, diagnosis, and management of LVAD adverse events and comorbidities

\begin{tabular}{|c|c|}
\hline Adverse event & Management considerations \\
\hline \multicolumn{2}{|l|}{ Pump thrombosis } \\
\hline \multirow[t]{2}{*}{ Prevention $^{18}$} & Aspirin: $81-325 \mathrm{mg}, 2$ to 5 days after implantation \\
\hline & $\begin{array}{l}\text { Anticoagulation: Heparin bridge or LMWH as chest tube output decreases, } 1-2 \text { days post-op goal APTT } 40-45 \text {, increase to } \\
60-80 \text { if no bleeding; INR goal 2.0-2.5 with Coumadin, } 5-7 \text { days post-op. }\end{array}$ \\
\hline \multirow[t]{4}{*}{ Treatment } & Early diagnosis with any worsening heart failure, thrombotic event, unexplained pump changes \\
\hline & $\begin{array}{l}\text { Increase in LDH level, increase in plasma free hemoglobin, device/log file analysis. Consider CTA to assess outflow cannula in } \\
\text { HM3. }\end{array}$ \\
\hline & HVAD — thrombolysis attempt if patient stable with low bleeding risk \\
\hline & HM2 and in some HVAD patients - pump exchange, readdress goals of care \\
\hline \multicolumn{2}{|l|}{ Stroke } \\
\hline Hemorrhagic & Discontinuation or reversal of anticoagulation; MAP $<90 \mathrm{mmHg}$; neurosurgical evaluation \\
\hline \multirow[t]{2}{*}{ Ischemic } & Neurology consultation, consider thrombectomy/thrombolysis \\
\hline & Determine etiology. Consider pump, outflow, LV, or atrial appendage thrombus if embolic. MAP $<90 \mathrm{mmHg}$. \\
\hline \multirow[t]{3}{*}{$\begin{array}{l}\text { Gastrointestinal } \\
\text { bleeding }\end{array}$} & $\begin{array}{l}\text { Consider discontinuation of anticoagulation or antiplatelet therapy if severe or recurrent; reversal of anticoagulation in life } \\
\text { threatening bleeding. }\end{array}$ \\
\hline & $\begin{array}{l}\text { Consider GI evaluation, including upper or lower endoscopy, video capsule next. There is decreased utility of repeated scopes } \\
\text { with frequent recurrent bleeds }\end{array}$ \\
\hline & Consider adding ACEi/ARB if absent; possible use of octreotide ${ }^{* *}$, thalidomide ${ }^{* *}$, estrogen ${ }^{* *}$ (**limited data to support it) \\
\hline \multirow[t]{3}{*}{ Driveline infection } & Prevention-repeat patient and caregiver teaching. \\
\hline & Frequent skin examinations; possible ultrasound/CT imaging; blood and tissue cultures \\
\hline & Infectious Disease consultation; Consider suppressive antibiotics if recurrent. In severe cases consider pump exchange. \\
\hline \multirow[t]{3}{*}{ Right heart failure } & $\begin{array}{l}\text { Consider if LV/pump is underfilled (e.g., low PI or variability), unexplained edema, kidney dysfunction, or congestive } \\
\text { hepatopathy in the setting of elevated right filling pressures. }\end{array}$ \\
\hline & $\begin{array}{l}\text { Right heart catheterization and echocardiography to aid diagnosis; assess contribution from } \\
\text { tricuspid regurgitation }\end{array}$ \\
\hline & Treat underlying pulmonary hypertension; diuresis; consider IV inotropes, possible digoxin; RVAD if severe \\
\hline Hypertension & MAP goal < 90; ACEi/ARB, hydralazine and low dose beta-blockers first line \\
\hline
\end{tabular}

patients with pump thrombosis, goals of care should be readdressed.

\section{Gastrointestinal Bleeding}

A significant number of cf-LVAD patients (up to 60\%) experience gastrointestinal (GI) bleeding throughout the course of their support with the device [53, 54]. Although some patients have preoperative GI bleeding issues that carry forward after LVAD, a majority of patients develop bleeding as a de novo issue $[55,56]$. In part, prior anatomical substrates for bleeding may simply be unmasked after cf-LVAD implantation via blood trauma leading to decreased platelet count or function and von Willebrand deficiency [53]. However, AVM formation may also be induced via stimulation of proangiogenic factors that are induced by the rheology of non-pulsatile blood flow in the distal tissues. Moreover, most LVAD patients are on chronic anticoagulation and antiplatelet therapies that further increase the risk of bleeding.

Given the high prevalence of this complication and its effect on quality of life, a number of novel therapeutic strategies have been evaluated with varying success to prevent recurrent GI bleeding. In two recent observational studies, the use of either angiotensin receptor blockade (ARB) or angiotensin-converting enzyme (ACE) inhibitor therapy was associated with reduced AVM-related GI bleeding in LVAD recipients [57, 58]. The proposed mechanism is associated with the reduction of angiogenesis related to transforming growth factor (TGF)- $\beta$ and angiopoietin-2 pathway activation. Other retrospective studies have shown some beneficial effect for treatment with digoxin [59] and omega-3 [60] in the prevention of GI bleeding. LVAD speed adjustments, octreotide, thalidomide, and estrogen therapy have also all been utilized in case series to reduce the incidence of GI bleeding in patients with recurrent bleeding [60-62]. However, these therapies may increase the risk of pump thrombosis. 


\section{Right Heart Failure}

Following LVAD implantation, up to $40 \%$ of patients develop early or acute right heart failure [63], which may affect the short- and long-term survival. Pre-existing RV dysfunction co-occurs in most patients with chronic LV dysfunction and is a risk factor for postoperative mortality $[11,64,65]$, yet the LVAD itself seems to unmask or exacerbate RV dysfunction. For decades, this was understood as a phenomenon that occurred early after LVAD. More recent reports have also described a "late right heart failure" phenotype occurring weeks to months after LVAD, with risk factors that are less well understood [66-68].

The underlying causal mechanisms for the development of right heart failure are likely multi-factorial. It is unclear why RV function unravels after LVAD, even as pulmonary artery impedance decreases from LV decongestion [69]. Some theories relate it at least in part to unfavorable changes in $\mathrm{RV}$ geometry: tethering and leftward shift of the interventricular septum leading to decreased RV systolic efficiency and tricuspid annulus distortion leading to worsening tricuspid regurgitation. Coupled to this is an increased venous return [70] and a deleterious loss of pericardial restraint seen in multiple types of cardiac surgery [71]. Moreover, load-independent toxicity to the RV also occurs that is not ameliorated by titration of LVAD speed, volume status, or pulmonary vascular resistance. Prediction of right heart failure in a number of risk scores derived from preoperative variables has had limited success $[72,73]$, though a recent single-center study has shown that the use of preoperative RV strain imaging may serve as a reliable prediction tool of this complication [74].

Survival and quality of life are worse among patients with right heart failure [75], and outcomes remain poor even when adverse RV hemodynamics are targeted with inotropes, pulmonary vasodilators, diuretics, and mechanical right ventricular support [76]. Durable biventricular support for severe right heart failure can be implemented with the addition of a temporary or durable right ventricular assist device (RVAD). Unplanned/late RVAD support appears less well tolerated than planned support at the time of LVAD insertion [77, 78], although these observations are challenged by potential selection bias and confounding by indication. Temporary percutaneous RVADs have been used to support hemodynamic recovery of the RV [79-81], but no survival benefit has been demonstrated in a randomized trial. Further studies are needed to allow better understanding of the pathophysiology and precipitants of right heart failure with LVAD.

\section{Device-Related Infections}

The risk of infection among LVAD recipients remains a major concern. Up to $50 \%$ of LVAD patients will experience an infectious complication [82], which constitute the third leading cause for LVAD readmission and are associated with a higher mortality rate and risk of stroke $[83,84]$. The International Society for Heart and Lung Transplantation (ISHLT) identified three primary categories of infection in LVAD recipients: (1) VAD-specific infections such as driveline (DLI) or pump pocket infections, (2) VAD-related infections such as sternal-wound infections or bloodstream infections, and (3) non-VAD infections such as cholecystitis or urinary tract infections. The clinical presentation of VAD infections may be nonspecific and misleading, with symptoms such as lethargy, fatigue, or anorexia, with or without fever or elevated white blood count. Treatment and suppression of infections depend on the category of infection, its location and extent, and the involved pathogen and should be managed in consultation with infectious disease specialists.

DLIs are the most common type of VAD-related infection. As prosthetic material exits the skin, it becomes a conduit for the entry of bacteria and an ideal environment for the formation of bacterial biofilms. Superficial DLI manifests with erythematous or purulent skin changes, thus regular inspection of the site must occur with dressing removal. Assessing the involvement of deeper structures remains challenging, as imaging modalities such as $\mathrm{CT}$ are subject to significant artifacts and ultrasound sensitivity for small fluid pockets are limited [85-87]. Use of ${ }^{18} \mathrm{~F}$-fluorodeoxyglucose PET/CT has been shown to improve sensitivity and specificity of DLI diagnosis in select patients [88]. Treatment decisions are patient-specific and currently lack comprehensive guidelines. Oral doxycycline-based regimens have had success in treating early localized infection [87], but the possibility of more widespread or polymicrobial infection requiring admission for broad-spectrum intravenous antibiotics should be entertained early in order to minimize the progression to intractable DLI requiring device exchange. Suppressive antibiotics for recurrent infection should also be considered [89].

\section{Valvular Regurgitation}

A major obstacle to the success of long-term LVAD support is the ability of the native heart and cardiac valves to withstand changes in hemodynamic load that are introduced with LVAD therapy. The response of each cardiac valve to LVAD implantation varies in the acute postoperative setting and can evolve over time. In general, aortic insufficiency (AI) and tricuspid regurgitation (TR) with greater than moderate severity usually require correction at the time of LVAD implantation, whereas functional mitral regurgitation (MR) is likely to improve without correction and correction has not been associated with improved outcomes [90]. Primary or severe functional MR is the exception, as significant residual MR that fails to improve with LVAD implantation is associated with refractory pulmonary arterial hypertension, worse RV function, and shorter time to first hospitalization and death [91]. 
Untreated significant AI, in particular, is a contraindication to LVAD implantation as it creates a continuous channel of regurgitant blood flow that impedes LVAD efficiency and cardiac output [92]. The aortic valve can be safely corrected during the LVAD implantation with bioprosthetic valve replacement, leaflet repair, or oversewing of the valve [93]. Postoperatively, de novo or progressive AI can also develop over months to years. Early cases may be influenced by preoperative leaflet trauma from temporary percutaneous LVADs [94]. Later cases may be influenced by permanent closure of the aortic valve due to excessive LV unloading, which is associated with a greater prevalence of de novo AI when compared to intermittent or complete opening.

\section{Improving Quality of Life}

Quality of life (QOL) with an LVAD remains critically important, particularly as DT LVAD patients are living longer with fewer episodes of device malfunction. For many patients, merely extending life without improving QOL may not be desirable [7]. Beyond the obvious impact of adverse events and frequent hospitalizations, issues related to quality of life in LVAD patients generally fall into two categories: (1) impaired functional status and exercise capacity and (2) psychosocial distress. There are several ways that providers can and should engage each of these categories in order to improve patient QOL.

First, although the LVAD improves cardiac output soon after implantation, several studies have shown that peak oxygen consumption (i.e., peak VO2) remains diminished. In many patients, peak VO2 after LVAD may be no different than preoperative peak VO2 $[95,96]$. The reasons for continued exercise impairment are multifactorial, related to a variety of cardiac and non-cardiac parameters: blood volume, heart rate, chronotropic response, cardiac pacing modality, aortic stiffness, concurrent medications, vascular tone, skeletal muscle function, right heart function, valvular dysfunction, poor left ventricular reserve, and differences in the H-Q curve of different LVAD platforms [97-103]. Given the multifactorial etiology of impaired exercise and functional capacity, referral to cardiac rehabilitation should be universally implemented following LVAD implantation - the benefit of which has been shown in a number of observational studies [104]. Secondly, because pump speed remains fixed between clinical encounters, all patients should undergo periodic ramped speed optimization to ensure the LV is optimally - but not excessively unloaded. Traditionally, echocardiography has been used to adjust LVAD speed to achieve proper unloading in the HM2, but recent pilot data have stimulated interest in the possible added benefit of hemodynamic speed optimization [105].

Second, psychosocial distress is common among LVAD patients, and many patients report that life with an LVAD did not meet their pre-implantation expectations [106]. Although many factors contribute to this distress, patients and their caregivers benefit from the inclusion of psychological, social, and palliative care services as part of the interdisciplinary team before and after LVAD implantation. In the VAD Decision Aid (VADDA) trial, the utility of a paperbased shared-decision aid prior to LVAD was associated with greater satisfaction with life after LVAD [107], and a multimodality tool is being studied in the DECIDE-LVAD trial [108]. After LVAD, patients reported an improved quality of life when clinicians were able to hold ongoing open conversations about goals of care with realistic expectations [7]. This process improves patient autonomy and more aptly clarifies patients' goals of care regarding critical end-of-life decisions.

\section{Additional Management Considerations}

Management of DT LVAD patients requires multidisciplinary coordination between cardiologists, surgeons, intensivists, anesthesiologists, nurses, VAD coordinators, palliative care specialists, emergency physicians, consultants, social workers, physical therapists, perfusionists, nutritionists, and financial coordinators [109]. To succeed, programs must have a core of dedicated physician leaders with training and experience in mechanical circulatory support, including advanced heart failure and transplant cardiologists and cardiothoracic surgeons. Provider certifications for these specialties are required through the American Board of Internal Medicine and the American Board of Thoracic Surgery after 6 to 8 years of respective postgraduate subspecialty training, and longitudinal continuing education specific to LVADs is necessary given the rapidity of discovery and technological improvements in the field. Program certification is required through the Center for Medicare and Medicaid Services (CMS) and the Joint Commission. CMS requires programs to implant a minimum of 10 VADs or total artificial hearts over a 3-year period to qualify for reimbursement, although greater than 20 implantations per year may be associated with improved riskadjusted survival and length of stay [110,111].

Successful programs must also engage patients and their caregivers as active participants in their healthcare. However, the sheer complexity of homecare regimens is often overwhelming for patients in spite of numerous formal training sessions, which can result in poor compliance and increased rates of adverse outcomes. Creative solutions to better empower patients are being evaluated in several clinical trials, including video simulations that teach self-management [112] or smartphone applications that prompt daily tasks while tracking inputs like vital signs and VAD parameters [113]. Telemedicine with video conferencing may help patients better troubleshoot some problems at home, reducing the total 
number of clinic visits or hospitalizations. Lastly, various strategies for remote monitoring could be beneficial, including the use of implantable pulmonary artery sensors currently being evaluated in the Intellect 2 trial using the CardioMEMS device.

\section{Future Directions}

Several improvements are desired in LVAD platforms that would address current limitations in the long-term care of LVAD patients and will improve both quality life and survival. First, a fully implanted device would address ongoing vulnerabilities with the driveline to infections and trauma. The primary limitation of this is device power, which at present requires an externalized driveline. However, wireless power systems are on the horizon and there was a recent first-inhuman demonstration of a Jarvik 2000 pump (Jarvik Heart, Inc., New York, NY) that was fully implanted in a patient in Kazakhstan using wireless coplanar energy transfer [114]. Second, activity-responsive devices are desired. Rateresponsive pacemakers have existed for decades, but pump technology requires more nuanced interaction with the pump that can be adapted to multiple physiologic situations. Lastly, significant improvements in biventricular support are needed. Compared to LVAD support alone, significant challenges remain with biventricular support platforms that have thus far limited more widespread use [115].

\section{Conclusions}

Mechanical support options for the DT patient have undergone tremendous strides since the initial implantation of pulsatile-flow pumps at the turn of the century. The evidence that cf-LVADs improve device durability and survival of DT patients is clear, and landmark improvements in pump outcomes recently established in the ENDURANCE and MOMENTUM trials with the HVAD and HM3 have greatly advanced the field. Following these technological improvements, there has been a revival of interest in several fundamental physiologic questions: what role does augmented pulsatility play in end-organ function [116], RV performance, or reverse remodeling of the left ventricle? Can anticoagulation targets be safely lowered in order to improve bleeding events? What role do neurohormonal therapies play in the long-term outcomes and likelihood of cardiac recovery when combined with cf-LVAD LV offloading? The answers to these questions will be both conceptually interesting and of great importance to patient care.

As patients live longer on mechanical support platforms, providers must never lose focus of the patient experience. LVAD-related adverse events continue to limit the full potential of these devices. Moreover, patients living with an LVAD have many more concerns than are represented in primary or secondary outcomes in major trials. Quality of life and functional status, though improved with LVADs, remain limited and prevent a wider expansion of DT LVAD use earlier in the care of patients with advanced heart failure. New platforms must be developed that can be fully internalized and that allow greater responsiveness to exercise or other changing physiologic demands, and strategies that lead to recovery of underlying cardiac function should continue to be pursued among all patients implanted with these devices.

\section{Compliance with Ethical Standards}

Conflict of Interest Dr. Hanff is supported by an NIH Cardiopulmonary Epidemiology T32 Training Grant (HL-007891). Dr. Birati receives paid consulting fees from American Regent Inc.

Human and Animal Rights and Informed Consent All reported studies/ experiments with human or animal subjects performed by the authors have been previously published and complied with all applicable ethical standards (including the Helsinki declaration and its amendments, institutional/national research committee standards, and international/national/institutional guidelines).

\section{References}

Papers of particular interest, published recently, have been highlighted as:

- Of importance

•. Of major importance

1. Savarese G, Lund LH. Global public health burden of heart failure. Card Fail Rev. 2017;3(1):7-11.

2. Birati EY, Jessup M. Left ventricular assist devices in the management of heart failure. Card Fail Rev. 2015;1(1):25.

3.• Rose EA, Gelijns AC, Moskowitz AJ, Heitjan DF, Stevenson LW, Dembitsky W, et al. Long-term use of a left ventricular assist device for end-stage heart failure. N Engl J Med. 2001;345(20): 1435-43.

4. Vorovich E. The mechanical revolution. J Card Fail. 2018;24(5): 335-6.

5.• Slaughter MS, Rogers JG, Milano CA, Russell SD, Conte JV, Feldman D, et al. Advanced heart failure treated with continuous-flow left ventricular assist device. N Engl J Med. 2009;361(23):2241-51 HeartMate 2 DT Trial.

6. Kormos RL, Cowger J, Pagani FD, Teuteberg JJ, Goldstein DJ, Jacobs JP, et al. The Society of Thoracic Surgeons Intermacs Database annual report: evolving indications, outcomes, and scientific partnerships. Ann Thorac Surg. 2019;107(2):341-53 Most recent STS/INTERMACS report.

7. Adams EE, Wrightson ML. Quality of life with an LVAD: a misunderstood concept. Heart Lung. 2018;47(3):177-83 Good paper on QOL in LVAD.

8. Warraich HJ, Allen LA, Blue LJ, Chaussee EL, Thompson JS, McIlvennan CK, et al. Comorbidities and the decision to undergo or forego destination therapy left ventricular assist device implantation: an analysis from the trial of a shared decision support 
intervention for patients and their caregivers offered destination therapy for end-stage heart failure (DECIDE-LVAD) study. Am Heart J. 2019;213:91-6.

9. Cowger JA, Grafton G. Candidate selection for durable mechanical circulatory support. Cardiol Clin. 2018 Nov;36(4):487-94.

10. Levy WC, Mozaffarian D, Linker DT, Sutradhar SC, Anker SD, Cropp AB, et al. The Seattle Heart Failure Model. Circulation. 2006 Mar 21;113(11):1424-33.

11. Birati EY, Hanff TC, Maldonado D, Grandin EW, Kennel PJ, Mazurek JA, et al. Predicting long term outcome in patients treated with continuous flow left ventricular assist device: the PennColumbia Risk Score. J Am Heart Assoc. 2018;20:7(6).

12. Rich JD, Burkhoff D. HVAD flow waveform morphologies: theoretical foundation and implications for clinical practice. ASAIO J. 2017;63(5):526-35.

13. Pennings KAMA, Martina JR, Rodermans BFM, Lahpor JR, van de Vosse FN, de Mol BAJM, et al. Pump flow estimation from pressure head and power uptake for the HeartAssist5, HeartMate II, and HeartWare VADs. ASAIO J. 2013;59(4):420-6.

14. Moazami N, Fukamachi K, Kobayashi M, Smedira NG, Hoercher $\mathrm{KJ}$, Massiello A, et al. Axial and centrifugal continuous-flow rotary pumps: a translation from pump mechanics to clinical practice. J Heart Lung Transplant. 2013;32(1):1-11 Good summary of pump mechanics, differences between axial/centrifugal pump.

15. Kirklin JK, Naftel DC, Kormos RL, Pagani FD, Myers SL, Stevenson LW, et al. Interagency registry for mechanically assisted circulatory support (INTERMACS) analysis of pump thrombosis in the HeartMate II left ventricular assist device. J Heart Lung Transplant. 2014;33(1):12-22.

16. Starling RC, Moazami N, Silvestry SC, Ewald G, Rogers JG, Milano CA, et al. Unexpected abrupt increase in left ventricular assist device thrombosis. N Engl J Med. 2014;370(1):33-40.

17. Uriel N, Han J, Morrison KA, Nahumi N, Yuzefpolskaya M, Garan AR, et al. Device thrombosis in HeartMate II continuousflow left ventricular assist devices: a multifactorial phenomenon. J Heart Lung Transplant. 2013;33:51-9.

18. Maltais S, Kilic A, Nathan S, Keebler M, Emani S, Ransom J, et al. Prevention of HeartMate II pump thrombosis through clinical management: the PREVENT multi-center study. J Heart Lung Transplant. 2017;36(1):1-12.

19.• Mehra MR, Uriel N, Naka Y, Cleveland JC, Yuzefpolskaya M, Salerno CT, et al. A fully magnetically levitated left ventricular assist device - final report. N Engl J Med. 2019;380(17):1618 27 HeartMate 3 trial.

20. Schroder JN, Milano CA. A tale of two centrifugal left ventricular assist devices. 2017

21. Pagani FD. Continuous-flow rotary left ventricular assist devices with "3rd generation" design. Semin Thorac Cardiovasc Surg. 2008;20(3):255-63.

22. Rich JD, Burkhoff D. HVAD flow waveform morphologies. ASAIO J. 2017;63(5):526-35.

23. Chatterjee A, Feldmann C, Dogan G, Hanke JS, Ricklefs M, Deniz E, et al. Clinical overview of the HVAD: a centrifugal continuous-flow ventricular assist device with magnetic and hydrodynamic bearings including lateral implantation strategies. J Thorac Dis. 2018;10(S15):S1785-9.

24. Meyer AL, Malehsa D, Budde U, Bara C, Haverich A, Strueber M. Acquired von Willebrand syndrome in patients with a centrifugal or axial continuous flow left ventricular assist device. JACC Hear Fail. 2014;2(2):141-5.

25. Zimpfer D, Strueber M, Aigner P, Schmitto JD, Fiane AE, Larbalestier R, et al. Evaluation of the HeartWare ventricular assist device Lavare cycle in a particle image velocimetry model and in clinical practice. Eur J Cardiothorac Surg. 2016;50(5):839-48.
26. Strueber M, Larbalestier R, Jansz P, Zimpfer D, Fiane AE, Tsui S, et al. Results of the post-market registry to evaluate the HeartWare left ventricular assist system (ReVOLVE). J Heart Lung Transplant. 2014;33(5):486-91.

27. Kumar J, Elhassan A, Dimitrova G, Essandoh M. The Lavare cycle: a novel pulsatile feature of the HVAD continuous-flow left ventricular assist device. J Cardiothorac Vasc Anesth. 2019;33(4): $1170-1$.

28.• Rogers JG, Pagani FD, Tatooles AJ, Bhat G, Slaughter MS, Birks EJ, et al. Intrapericardial left ventricular assist device for advanced heart Failure. N Engl J Med. 2017;376(5):451-60 ENDURANCE, HVAD trial.

29. Teuteberg JJ, Slaughter MS, Rogers JG, McGee EC, Pagani FD, Gordon R, et al. The HVAD left ventricular assist device: risk factors for neurological events and risk mitigation strategies. JACC Heart Fail. 2015;3(10):818-28.

$30 . \bullet$ Milano CA, Rogers JG, Tatooles AJ, Bhat G, Slaughter MS, Birks EJ, et al. HVAD: The ENDURANCE supplemental trial. JACC Hear Fail. 2018;6(9):792-802 ENDURANCE Supplemental trial.

31. Mcgee E, Danter M, Strueber M, Mahr C, Mokadam NA, Wieselthaler G, et al. Evaluation of a lateral thoracotomy implant approach for a centrifugal-flow left ventricular assist device: the LATERAL clinical trial. J Heart Lung Transplant. 2019;38:344 51.

32. Bourque K, Cotter C, Dague C, Harjes D, Dur O, Duhamel J, et al. Design rationale and preclinical evaluation of the HeartMate 3 left ventricular assist system for hemocompatibility. ASAIO J. 2016;62(4):375-83.

33. Cowger J, Pagani FD, Haft JW, Romano MA, Aaronson KD, Kolias TJ. The development of aortic insufficiency in left ventricular assist device-supported patients. Circ Heart Fail. 2010;3(6): 668-74.

34. Demirozu ZT, Radovancevic R, Hochman LF, Gregoric ID, Letsou GV, Kar B, et al. Arteriovenous malformation and gastrointestinal bleeding in patients with the HeartMate II left ventricular assist device. J Heart Lung Transplant. 2011;30(8):849-53.

35. Stansfield WE, Rao V. HeartMate 3: facing the challenge of past success. J Thorac Cardiovasc Surg. 2016;152(3):683-5.

36. Heatley G, Sood P, Goldstein D, Uriel N, Cleveland J, Middlebrook D, et al. Clinical trial design and rationale of the multicenter study of MagLev technology in patients undergoing mechanical circulatory support therapy with HeartMate 3 (MOMENTUM 3) investigational device exemption clinical study protocol. J Heart Lung Transplant. 2016;35:528-36.

37. Goldstein DJ, Mehra MR, Naka Y, Salerno C, Uriel N, Dean D, et al. Impact of age, sex, therapeutic intent, race and severity of advanced heart failure on short-term principal outcomes in the MOMENTUM 3 trial. J Heart Lung Transplant. 2018;37(1):7-14.

38. Mehra MR. The burden of haemocompatibility with left ventricular assist systems: a complex weave. Eur Heart J. 2019;40(8): 673-7 Hemocompatibility concept explained.

39. Uriel N, Colombo PC, Cleveland JC, Long JW, Salerno C, Goldstein DJ, et al. Hemocompatibility-related outcomes in the MOMENTUM 3 trial at 6 months. Circulation. 2017;135(21): 2003-12.

40. Mehra MR, Salerno C, Naka Y, Uriel N, Cleveland JC, Horstmanshof D, et al. A tale of the twist in the outflow graft: an analysis from the MOMENTUM 3 trial. J Heart Lung Transplant. 2018;37(11):1281-4.

41. Kirkpatrick JN, Mahr C, Beckman J, Bjelkengren J, Dudzinski DM. Responding to ventricular assist device recalls: an ethical guide for mechanical circulatory support programs. ASAIO J 201918

42. Colombo PC, Mehra MR, Goldstein DJ, Estep JD, Salerno C, Jorde UP, et al. Comprehensive analysis of stroke in the long- 
term cohort of the MOMENTUM 3 study. Circulation. 2019;139(2):155-68.

43. Birati EY, Rame JE. Left ventricular assist device management and complications. Crit Care Clin. 2014;30(3):607-27.

44. Young JB. Long-term mechanical circulatory support vs heart transplant: a half-century of progress, but when will the tin man arrive? J Card Fail. 2018;24(5):330-4.

45. Thenappan T, Stulak JM, Agarwal R, Maltais S, Shah P, Eckman $\mathrm{P}$, et al. Early intervention for lactate dehydrogenase elevation improves clinical outcomes in patients with the HeartMate II left ventricular assist device: insights from the PREVENT study. J Heart Lung Transplant. 2018;37(1):25-32.

46. Saeed D, Maxhera B, Albert A, Westenfeld R, Hoffmann T, Lichtenberg A. Conservative approaches for HeartWare ventricular assist device pump thrombosis may improve the outcome compared with immediate surgical approaches. Interact Cardiovasc Thorac Surg. 2016;23(1):90-5.

47. Birati EY, Quiaoit Y, Wald J, Kirkpatrick JN, Goldberg LR, Atluri $\mathrm{P}$, et al. Ventricular assist device thrombosis: a wide spectrum of clinical presentation. J Heart Lung Transplant. 2015;34(4):613-5.

48. Birati EY, Rame JE. Diagnosis and management of LVAD thrombosis. Curr Treat Options Cardiovasc Med. 2015;17(2):2 Good summary of pump thrombosis management.

49. Rame JE, Birati EY. HeartWare left ventricular assist device pump thrombosis: a shift away from ramp. JACC Hear Fail. 2015;3(11): 857-9.

50. Jorde UP, Aaronson KD, Najjar SS, Pagani FD, Hayward C, Zimpfer D, et al. Identification and management of pump thrombus in the HeartWare left ventricular assist device system: a novel approach using log file analysis. JACC Hear Fail. 2015;3(11): 849-56.

51. Upshaw JN, Kiernan MS, Morine KJ, Kapur NK, DeNofrio D. Incidence, management, and outcome of suspected continuousflow left ventricular assist device thrombosis. ASAIO J. 2016;62(1):33-9.

52. Muthiah K, Robson D, Macdonald PS, Keogh AM, Kotlyar E, Granger E, et al. Thrombolysis for suspected intrapump thrombosis in patients with continuous flow centrifugal left ventricular assist device. Artif Organs. 2013;37(3):313-8.

53. Gurvits GE, Fradkov E. Bleeding with the artificial heart: gastrointestinal hemorrhage in CF-LVAD patients. World J Gastroenterol. 2017;23(22):3945.

54. Marsano J, Desai J, Chang S, Chau M, Pochapin M, Gurvits GE. Characteristics of gastrointestinal bleeding after placement of continuous-flow left ventricular assist device: a case series. Dig Dis Sci. 2015;60(6):1859-67.

55. Stern DR, Kazam J, Edwards P, Maybaum S, Bello RA, D'Alessandro DA, et al. Increased incidence of gastrointestinal bleeding following implantation of the HeartMate II LVAD. J Card Surg. 2010;25(3):352-6.

56. Aggarwal A, Pant R, Kumar S, Sharma P, Gallagher C, Tatooles $\mathrm{AJ}$, et al. Incidence and management of gastrointestinal bleeding with continuous flow assist devices. Ann Thorac Surg. 2012;93(5):1534-40.

57. Houston BA, Schneider ALC, Vaishnav J, Cromwell DM, Miller $\mathrm{PE}$, Faridi KF, et al. Angiotensin II antagonism is associated with reduced risk for gastrointestinal bleeding caused by arteriovenous malformations in patients with left ventricular assist devices. J Heart Lung Transplant. 2017;36(4):380-5.

58. Schultz J, John R, Alexy T, Thenappan T, Cogswell R. Association between angiotensin II antagonism and gastrointestinal bleeding on left ventricular assist device support. J Heart Lung Transplant. 2018;38(4):469-71.

59. Vukelic S, Vlismas PP, Patel SR, Xue X, Shitole SG, Saeed O, et al. Digoxin is associated with a decreased incidence of angiodysplasia-related gastrointestinal bleeding in patients with continuous-flow left ventricular assist devices. Circ Heart Fail. 2018;11(8):e004899.

60. Imamura T, Nguyen A, Rodgers D, Kim G, Raikhelkar J, Sarswat $\mathrm{N}$, et al. Omega-3 therapy is associated with reduced gastrointestinal bleeding in patients with continuous-flow left ventricular assist device. Circ Heart Fail. 2018t;11(10):e005082.

61. Imamura T, Nguyen A, Kim G, Raikhelkar J, Sarswat N, Kalantari $\mathrm{S}$, et al. Optimal haemodynamics during left ventricular assist device support are associated with reduced haemocompatibilityrelated adverse events. Eur J Heart Fail. 2019;21(5):655-62.

62. Imamura T, Kinugawa K, Uriel N. Therapeutic strategy for gastrointestinal bleeding in patients with left ventricular assist device. Circ J. 2018;82(12):2931-8 Good review of GI bleeding therapies in LVAD.

63. Baumwol J, Macdonald PS, Keogh AM, Kotlyar E, Spratt P, Jansz $\mathrm{P}$, et al. Right heart failure and "failure to thrive" after left ventricular assist device: clinical predictors and outcomes. J Heart Lung Transplant. 2011;30(8):888-95.

64. Kiernan MS, Grandin EW, Brinkley M, Kapur NK, Pham DT, Ruthazer R, et al. Early right ventricular assist device use in patients undergoing continuous-flow left ventricular assist device implantation. Circ Heart Fail. 2017;10(10):e003863 1-10.

65. Grandin EW, Zamani P, Mazurek JA, Troutman GS, Birati EY, Vorovich E, et al. Right ventricular response to pulsatile load is associated with early right heart failure and mortality after left ventricular assist device. J Heart Lung Transplant. 2017;36(1): 97-105.

66. Baran DA, Mehra MR. Late-onset right heart failure after left ventricular assist device implant: quo vadis? J Heart Lung Transplant. 2017;36(1):26-7.

67. MacGowan GA, Schueler S. Right heart failure after left ventricular assist device implantation. Curr Opin Cardiol. 2012;27(3): 296-300.

68. Takeda K, Takayama H, Colombo PC, Yuzefpolskaya M, Fukuhara S, Han J, et al. Incidence and clinical significance of late right heart failure during continuous-flow left ventricular assist device support. J Heart Lung Transplant. 2015;34(8):1024 32 .

69. Tedford RJ. Determinants of right ventricular afterload ( 2013 Grover Conference series). Pulm Circ. 2014;4(2):211-9 Excellent discussion of RV afterload physiology.

70. Houston BA, Shah KB, Mehra MR, Tedford RJ. A new "twist" on right heart failure with left ventricular assist systems. J Heart Lung Transplant. 2017;36(7):701-7.

71. Unsworth B, Casula RP, Kyriacou AA, Yadav H, Chukwuemeka A, Cherian A, et al. The right ventricular annular velocity reduction caused by coronary artery bypass graft surgery occurs at the moment of pericardial incision. Am Heart J. 2010;159(2):314-22.

72. Bellavia D, Iacovoni A, Scardulla C, Moja L, Pilato M, Kushwaha SS, et al. Prediction of right ventricular failure after ventricular assist device implant: systematic review and meta-analysis of observational studies. Eur J Heart Fail. 2017;19(7):926-46.

73. Atluri P, Goldstone AB, Fairman AS, MacArthur JW, Shudo Y, Cohen JE, et al. Predicting right ventricular failure in the modern, continuous flow left ventricular assist device era. Ann Thorac Surg. 2013;96(3):857-64.

74. Liang LW, Birati EY, Justice C, Han Y. Right ventricular strain as a predictor of post-LVAD early right ventricular failure. In: International Society for Heart and Lung Transplantation. Orlando, Florida; 2019

75. Lampert BC, Teuteberg JJ. Right ventricular failure after left ventricular assist devices. J Heart Lung Transplant. 2015;34(9):112330.

76. Meineri M, Van Rensburg AE, Vegas A. Right ventricular failure after LVAD implantation: prevention and treatment. Best Pract Res Clin Anaesthesiol. 2012;26(2):217-29. 
77. Shehab S, Allida SM, Davidson PM, Newton PJ, Robson D, Jansz $\mathrm{PC}$, et al. Right ventricular failure post LVAD implantation corrected with biventricular support: an in vitro model. ASAIO J. 2017;63(1):41-7.

78. Yoshioka D, Takayama H, Garan RA, Topkara VK, Han J, Kurlansky P, et al. Contemporary outcome of unplanned right ventricular assist device for severe right heart failure after continuous-flow left ventricular assist device insertion. Interact Cardiovasc Thorac Surg. 2017;24(6):828-34.

79. Anderson MB, Goldstein J, Milano C, Morris LD, Kormos RL, Bhama J, et al. Benefits of a novel percutaneous ventricular assist device for right heart failure: the prospective RECOVER RIGHT study of the Impella RP device. J Heart Lung Transplant. 2015;34(12):1549-60.

80. Esposito ML, Bader Y, Morine KJ, Kiernan MS, Pham DT, Burkhoff D, et al. Mechanical circulatory support devices for acute right ventricular failure IN DEPTH. Circulation. 2017;136: 314-26.

81. Loforte A, Stepanenko A, Potapov EV, Musumeci F, Dranishnikov N, Schweiger M, et al. Temporary right ventricular mechanical support in high-risk left ventricular assist device recipients versus permanent biventricular or total artificial heart support. Artif Organs. 2013;37(6):523-30.

82. Topkara VK, Kondareddy S, Malik F, Wang I-W, Mann DL, Ewald GA, et al. Infectious complications in patients with left ventricular assist device: etiology and outcomes in the continuous-flow era. Ann Thorac Surg. 2010;90(4):1270-7.

83. Gordon RJ, Weinberg AD, Pagani FD, Slaughter MS, Pappas PS, Naka Y, et al. Prospective, multicenter study of ventricular assist device infections. Circulation. 2013;127(6):691-702.

84. Shah P, Birk SE, Cooper LB, Psotka MA, Kirklin JK, Barnett SD, et al. Stroke and death risk in ventricular assist device patients varies by ISHLT infection category: an INTERMACS analysis. J Heart Lung Transplant. 2019;38(7):721-30.

85. Dell'Aquila AM, Mastrobuoni S, Alles S, Wenning C, Henryk W, Schneider SRB, et al. Contributory role of fluorine 18fluorodeoxyglucose positron emission tomography/computed tomography in the diagnosis and clinical management of infections in patients supported with a continuous-flow left ventricular assist device. Ann Thorac Surg. 2016;101(1):87-94 discussion 94.

86. Levy DT, Minamoto GY, Da Silva R, Puius YA, Peck N, Goldstein D, et al. Role of gallium SPECT-CT in the diagnosis of left ventricular assist device infections. ASAIO J. 2015;61(1): e5-10.

87. Leuck A-M. Left ventricular assist device driveline infections: recent advances and future goals. J Thorac Dis. 2015;7(12): 2151-7.

88. Kanapinn P, Burchert W, Körperich H, Körfer J. 18F-FDG PET/ $\mathrm{CT}$-imaging of left ventricular assist device infection: a retrospective quantitative intrapatient analysis. J Nucl Cardiol. 2018;16.

89. Nienaber JJC, Kusne S, Riaz T, Walker RC, Baddour LM, Wright AJ, et al. Clinical manifestations and management of left ventricular assist device-associated infections. Clin Infect Dis. 2013;57(10):1438-48.

90. Choi JH, Luc JGY, Moncho Escrivá E, Phan K, Rizvi SSA, Patel $\mathrm{S}$, et al. Impact of concomitant mitral valve surgery with LVAD placement: systematic review and meta-analysis. Artif Organs. 2018;42(12):1139-47.

91. Kassis H, Cherukuri K, Agarwal R, Kanwar M, Elapavaluru S, Sokos GG, et al. Significance of residual mitral regurgitation after continuous flow left ventricular assist device implantation. JACC Hear Fail. 2017;5(2):81-8.

92. Gustafsson F, Rogers JG. Left ventricular assist device therapy in advanced heart failure: patient selection and outcomes. Eur J Heart Fail. 2017;19(5):595-602.
93. Atkins BZ, Hashmi ZA, Ganapathi AM, Harrison JK, Hughes GC, Rogers JG, et al. Surgical correction of aortic valve insufficiency after left ventricular assist device implantation. J Thorac Cardiovasc Surg. 2013;146(5):1247-52.

94. Rao SD, Johnson B, Medina V, Rame E, Goldberg L, Wald J, et al. Increased incidence of de novo aortic incompetence in patients supported with impella prior to LVAD implantation. In: International Society for Heart and Lung Transplantation. Orlando, Florida;

95. Leibner ES, Cysyk J, Eleuteri K, El-Banayosy A, Boehmer JP, Pae WE. Changes in the functional status measures of heart failure patients with mechanical assist devices. ASAIO J. 2013;59(2): 117-22.

96. Dunlay SM, Allison TG, Pereira NL. Changes in cardiopulmonary exercise testing parameters following continuous flow left ventricular assist device implantation and heart transplantation. J Card Fail. 2014;20(8):548-54.

97. Compostella L, Russo N, Setzu T, Compostella C, Bellotto F. Exercise performance of chronic heart failure patients in the early period of support by an axial-flow left ventricular assist device as destination therapy. Artif Organs. 2014;38(5):366-73.

98. Jakovljevic DG, George RS, Nunan D, Donovan G, Bougard RS, Yacoub $\mathrm{MH}$, et al. The impact of acute reduction of continuousflow left ventricular assist device support on cardiac and exercise performance. Heart. 2010;96(17):1390-5.

99. Jung MH, Gustafsson F. Exercise in heart failure patients supported with a left ventricular assist device. J Heart Lung Transplant. 2015;34(4):489-96.

100. Imamura T, Jeevanandam V, Kim G, Raikhelkar J, Sarswat N, Kalantari S, et al. Optimal hemodynamics during left ventricular assist device support are associated with reduced readmission rates. Circ Heart Fail. 2019;12(2):e005094.

101. Mirza KK, Cuomo K, Jung MH, Russell SD, Gustafsson F. Effect of heart rate reserve on exercise capacity in patients treated with a continuous left ventricular assist device. ASAIO J. 2019;24:1.

102. Martina J, Jonge N, Rutten M, Kirkels JH, Klöpping C, Rodermans B, et al. Exercise hemodynamics during extended continuous flow left ventricular assist device support: the response of systemic cardiovascular parameters and pump performance. Artif Organs. 2013;37(9):754-62.

103. Reiss N, Schmidt T, Workowski A, Willemsen D, Schmitto JD, Haverich A, et al. Physical capacity in LVAD patients: hemodynamic principles, diagnostic tools and training control. Int J Artif Organs. 2016;39(9):451-9.

104. Mahfood Haddad T, Saurav A, Smer A, Azzouz MS, Akinapelli A, Williams MA, et al. Cardiac rehabilitation in patients with left ventricular assist device. J Cardiopulm Rehabil Prev. 2017;37(6): 390-6.

105. Uriel N, Burkhoff D, Rich JD, Drakos SG, Teuteberg JJ, Imamura $\mathrm{T}$, et al. Impact of hemodynamic ramp test-guided HVAD speed and medication adjustments on clinical outcomes. Circ Heart Fail. 2019;12(4):e006067.

106. Kitko LA, Hupcey JE, Birriel B, Alonso W. Patients' decision making process and expectations of a left ventricular assist device pre and post implantation. Heart Lung. 2016;45(2):95-9.

107. Kostick KM, Bruce CR, Minard CG, Volk RJ, Civitello A, Krim $\mathrm{SR}$, et al. A multisite randomized controlled trial of a patientcentered ventricular assist device decision aid (VADDA trial). J Card Fail. 2018;24(10):661-71.

108. McIlvennan CK, Thompson JS, Matlock DD, Cleveland JC, Dunlay SM, LaRue SJ, et al. A multicenter trial of a shared decision support intervention for patients and their caregivers offered destination therapy for advanced heart failure: DECIDE-LVAD: rationale, design, and pilot data. J Cardiovasc Nurs. 2016;31(6): E8-20. 
109. Makdisi G, Makdisi PB, Bittner HB. How to establish a successful destination therapy ventricular assist device program. J Thorac Dis. 2017;9(4):932-5.

110. Shah N, Chothani A, Agarwal V, Deshmukh A, Patel N, Garg J, et al. Impact of annual hospital volume on outcomes after left ventricular assist device (LVAD) implantation in the contemporary era. J Card Fail. 2016;22(3):232-7.

111. Cowger JA, Stulak JM, Shah P, Dardas TF, Pagani FD, Dunlay $\mathrm{SM}$, et al. Impact of center left ventricular assist device volume on outcomes after implantation. JACC Hear Fail. 2017;5(10):691-9.

112. Barsuk J. Use of simulation to improve VAD self-management ClinicalTrials.gov NCT03073005 [Internet]. Accessed 21 July 2019.

113. Casida J. Self-management app for patients with left-ventricular assist devices - ClinicalTrials.gov NCT03049748 [Internet]. Accessed 21 July 2019

114. Pya Y, Maly J, Bekbossynova M, Salov R, Schueler S, Meyns B, et al. First human use of a wireless coplanar energy transfer coupled with a continuous-flow left ventricular assist device. J Heart Lung Transplant. 2019;38(4):339-43.

115. Pagani FD. Clinical implications of the total artificial heart: adversity and progress. J Heart Lung Transplant. 2018;37(11):1298300 .

116. Grosman-Rimon L, Billia F, Kobulnik J, Bar-Ziv SP, Cherney DZ, Rao V. The physiological rationale for incorporating pulsatility in continuous-flow left ventricular assist devices. Cardiol Rev. 2018;26(6):1.

Publisher's Note Springer Nature remains neutral with regard to jurisdictional claims in published maps and institutional affiliations. 